\title{
Initial response and subsequent course of Crohn's disease treated with elemental diet or prednisolone
}

\author{
D A Gorard, J B Hunt, J J Payne-James, K R Palmer, R G P Rees, M L Clark, M J G Farthing, \\ J J Misiewicz, D B A Silk
}

\begin{abstract}
Elemental diet is as effective as corticosteroids in the treatment of previously untreated Crohn's disease. It is unclear whether a poor nutritional state is a prerequisite for efficacy of elemental diet, whether previously treated patients respond as well, or how duration of remission using elemental diet compares with corticosteroid induced remission. Forty two patients with active Crohn's disease were stratified for nutritional state and randomised to receive Vivonex TEN $2 \cdot 1 \mathrm{l} /$ day for four weeks, or $0.75 \mathrm{mg}$ prednisolone $/ \mathrm{kg} /$ day for two weeks and subsequent reducing doses. Nine of $22(41 \%)$ patients assigned to nutritional treatment were intolerant of the diet. Thirty patients completed four weeks treatment. Disease activity decreased on elemental diet from mean (SEM) 4.8(0.9) to 1.7 (0.6), p <0.05, and on prednisolone from $5 \cdot 3(0.5)$ to $1.9(0.6)$, $p<0.05$. For each treatment, nourished and malnourished patients responded similarly. Patients with longstanding disease responded as well as newly diagnosed patients. The probability of maintaining remission at six months was 0.67 after prednisolone, 0.28 after elemental diet, and at one year was 0.35 after prednisolone and 0.09 after elemental diet, $\mathbf{p}<\mathbf{0 . 0 5}$. When tolerated, elemental diet is as effective in the short term as prednisolone in newly and previously diagnosed Crohn's disease, and its benefit is independent of nutritional state. The subsequent relapse rate after elemental diet induced remission, however, is greater than after treatment with prednisolone.
\end{abstract}

(Gut 1993; 34: 1198-1202)

Crohn's disease is commonly associated with undernutrition,' which is often most evident when the disease is active. Nutritional treatment may have a primary therapeutic role in active Crohn's disease in addition to its proven value as a supportive measure in the overall management of the disease..$^{24}$ Chemically defined 'elemental' diets containing nutrients in simple, easily assimilable form with nitrogen provided as free amino acids, carbohydrate as simple sugars or glucose polymers, and fat present in very small amounts, were initially used as nutritional support in patients with Crohn's disease. Subsequently, they have been reported to be as effective as corticosteroids in treating patients with active Crohn's disease, ${ }^{56}$ and one controlled, but non-randomised trial suggested that elemental diet was actually superior to corticosteroid treatment. ${ }^{7}$ In childhood Crohn's disease, attainment of remission using dietary means is particularly attractive, as the growth retarding effects of steroids can be avoided. Elemental diet has been shown to be as beneficial as corticosteroid treatment in children with Crohn's disease. ${ }^{8}$

It is not clear, however, from these published studies whether elemental diet is as efficacious as steroids in previously treated adults with active Crohn's disease. The only prospective trial directly comparing elemental diet with steroids, which included adult patients who had received treatment for Crohn's disease in the past, also entailed administration of antibiotics during the 10 day treatment with elemental diet. ${ }^{6}$ In addition it is not known whether the influence of nutritional treatment on the disease process is as beneficial in nourished as in undernourished patients. Similarly, the longterm outcome of adult patients treated with elemental diet has not been compared with the outcome after steroid treatment in a prospective fashion. If this treatment changes the fundamental disease process, a prolonged period of remission might be expected in these patients. We have undertaken a randomised trial of elemental diet $v$ prednisolone, to consider these points, in patients with newly diagnosed or recurrent attacks of Crohn's disease, and followed up the patients for one year after treatment or until relapse.

\section{Methods}

Patients with active Crohn's disease requiring hospital admission were considered for entry into the study. Patients were recruited from three centres, St Bartholomew's and Central Middlesex Hospitals in London, and Western General Hospital in Edinburgh. The diagnosis of Crohn's disease was made by colonoscopy with biopsy or characteristic radiological appearances on barium studies. Active Crohn's disease was defined as at least one of the following: abdominal pain causing severe limitation of activity, diarrhoea (at least 3 loose stools/day), weight loss of more than $2 \mathrm{~kg}$ in the past month, or at least two of the following laboratory abnormalities: haemoglobin $<12.5 \mathrm{~g} / \mathrm{dl}$ in men $(<10.5 \mathrm{~g} / \mathrm{dl}$ in women), erythrocyte sedimentation rate $>20$ $\mathrm{mm} / \mathrm{h}$, serum albumin $<35 \mathrm{~g} / \mathrm{l}$.

Patients were excluded if they had evidence of intestinal obstruction, previous gastric surgery, a contraindication to steroid treatment, or had been receiving more than $7.5 \mathrm{mg}$ prednisolone/ day at the time of relapse. Patients fulfilling the entry criteria were stratified before randomisation according to whether they were malnourished or not. Patients were considered malnourished if they (a) had lost more than $10 \%$ usual body weight or had a serum albumin of 
$<30 \mathrm{~g} / \mathrm{l}$; and (b) also had a triceps skinfold thickness (TSF) of $<90 \%$ adult reference range or a mid arm muscle circumference (MAMC) $<90 \%$ reference range. ${ }^{9}$ Informed consent was obtained from all patients and the study protocol approved by the Research Ethical Committees of the participating centres.

Patients were randomised to receive either prednisolone $0.75 \mathrm{mg} / \mathrm{kg}$ body weight daily for two weeks followed by subsequent reducing doses, or elemental diet (Vivonex TEN, Norwich Eaton) as sole treatment for four weeks. The nitrogen source in Vivonex TEN is amino acids comprising $15 \cdot 3 \%$ of its energy value, carbohydrate as glucose polymers (maltodextrin), makes up $82 \cdot 2 \%$ of its energy value, and safflower oil contributes just $2 \cdot 5 \%$ of the total energy as fat. Patients receiving elemental diet consumed a minimum of $2 \cdot 1$ litres of standard dilution Vivonex daily, providing $2100 \mathrm{kcal}$ and $12 \mathrm{~g}$ nitrogen. This minimum daily intake was reached by day 3 , and 'starter regimens' using less than full strength of the feed were not used. ${ }^{10}$ Those who could not take this minimum daily requirement orally were fed by fine bore nasogastric tube. All other food except water and tea or coffee without milk was prohibited. Patients receiving elemental diet remained in hospital for at least 10 days to ensure compliance. After discharge they were reviewed at weekly intervals and the volume of feed consumed was recorded daily throughout the four week period. After four weeks treatment with elemental diet, normal diet was reintroduced. Patients assigned to receive steroids consumed an unrestricted diet and were asked to record their food intake during the first four weeks. After the first two weeks of prednisolone, the daily dose was steadily reduced to zero over the ensuing weeks. Patients taking sulphasalazine at the time of onset of relapse continued on this drug.

Before treatment was started (week 0), clinical disease severity was assessed using a simple disease activity index (DAI). ${ }^{1 "}$ Anthropometric measurements of mid arm circumference (MAC), TSF, MAMC, weight and height were made and expressed as percentage standard MAC, MAMC, TSF, and percentage ideal body

TABLE I Comparison of the two treatment groups at randomisation

\begin{tabular}{|c|c|c|}
\hline & Prednisolone $(n=20)$ & Elemental diet $(n=22)$ \\
\hline Age (mean (SEM)) (yrs) & $32 \cdot 5(3 \cdot 4)$ & $31 \cdot 6(3 \cdot 0)$ \\
\hline Range & $16-66$ & $16-75$ \\
\hline Sex & $7 \mathrm{M}, 13 \mathrm{~F}$ & $12 \mathrm{M}, 10 \mathrm{~F}$ \\
\hline \multicolumn{3}{|l|}{ Disease site } \\
\hline Small intestine & 6 & 7 \\
\hline Ileocolonic & 7 & 11 \\
\hline Colon & 7 & 4 \\
\hline Disease duration & 11 New, & $11 \mathrm{New}$, \\
\hline Nutritional state & 12 Nourished, 8 malnourished & 14 Nourished, 8 malnourished \\
\hline Weight (mean (SEM)) (kg) & $54 \cdot 8(3 \cdot 4)$ & $58 \cdot 8(3.4)$ \\
\hline$\%$ IBW & $89 \cdot 4(3 \cdot 8)$ & $90.0(3.8)$ \\
\hline$\%$ Standard MAC & $85 \cdot 5(3 \cdot 2)$ & $83.9(2 \cdot 8)$ \\
\hline$\%$ Standard TSF & $73 \cdot 2(7 \cdot 7)$ & $72 \cdot 9(7 \cdot 2)$ \\
\hline$\%$ Standard MAMC & $90.4(3.4)$ & $87 \cdot 3(2 \cdot 9)$ \\
\hline Disease activity index & $5 \cdot 5(0 \cdot 5)$ & $5 \cdot 14(0 \cdot 5)$ \\
\hline Haemoglobin (g/dl) & $11.9(0.48)$ & $11.8(0.43)$ \\
\hline $\operatorname{ESR}(\mathrm{mm} / \mathrm{h})$ & $47 \cdot 1(8 \cdot 2)$ & $41 \cdot 3(7 \cdot 5)$ \\
\hline $\mathrm{CRP}(\mathrm{mg} / \mathrm{l})$ & $72 \cdot 1(15 \cdot 8)$ & $50 \cdot 7(11 \cdot 1)$ \\
\hline Albumin $(g / l)$ & $34.8(1.26)$ & $35.6(0.98)$ \\
\hline
\end{tabular}

IBW $=$ ideal body weight, $\mathrm{MAC}=$ mid arm circumference, $\mathrm{TSF}=$ triceps skinfold thickness, $\mathrm{MAMC}=$ mid-arm muscle circumference, $\mathrm{ESR}=$ erythrocyte sedimentation rate, $\mathrm{CRP}=\mathrm{C}$-reactive protein weight (\%IBW). ${ }^{912}$ Laboratory measurements of haemoglobin, white cell count, lymphocyte count, erythrocyte sedimentation rate, albumin, urea, and C-reactive protein (CRP) were recorded. These assessments of DAI, anthropometric and laboratory measurements were repeated at week $1,2,3,4,8,12,16,28,40$, and 52 , or sooner if a relapse occurred. A relapse was defined as a clinical deterioration with an increase in DAI requiring (i) high dose steroids, or a return to high dose steroids in the case of patients still on tapering prednisolone doses, or (ii) surgery.

$\chi^{2}$ and Wilcoxon rank sum tests were used to compare the characteristics of the two treatment groups at randomisation. The response to treatment was assessed by Wilcoxon signed rank test. Results are expressed as mean (SEM). After treatment, the time to relapse within each treatment group was assessed by lifetable analysis, and the two survival curves obtained were compared using the log rank test. ${ }^{13}$

\section{Results}

Forty two patients (19 men) were entered into the study. Twenty two patients were randomised to receive elemental diet and 20 to receive prednisolone. Twenty two patients were newly diagnosed and 20 were patients with known Crohn's disease in relapse. Patients within each treatment group were well matched in terms of age, site and duration of disease, nutritional state, initial DAI, laboratory and anthropometric data (Table I)

\section{INITIAL FOUR WEEKS TREATMENT}

Of the 22 patients assigned to dietary treatment, nine $(41 \%)$ could not tolerate elemental diet whether given orally or nasogastrically. The reasons for non-compliance with the diet were its unpalatability and intolerance of a nasogastric tube. These patients were withdrawn from the trial and treated with corticosteroids. Three patients (two on elemental diet, one on prednisolone) deteriorated and required urgent colonic surgery within four weeks of entry.

The mean daily intake of Vivonex in those completing four weeks treatment was $2070 \mathrm{ml}$ $(2070 \mathrm{kcal})$. Dietary records of the patients treated with prednisolone were inadequate to make a valid assessment of nutritional intake. For the 30 patients completing four weeks treatment (19 treated with prednisolone, 11 with elemental diet), there were significant improvements in DAI and laboratory indicators of activity. The degree of improvement in both treatment groups was similar (Fig 1). Of the 19 patients completing four weeks prednisolone, 12 had been nourished and seven malnourished at randomisation. Of the 11 patients completing four weeks elemental diet, six were nourished and five malnourished at randomisation.

Despite the overall improvement in both groups, one patient on elemental diet and two on prednisolone achieved only a partial remission at four weeks. In considering these patients, and those requiring early surgery, a failure to achieve complete remission at four weeks was seen in 

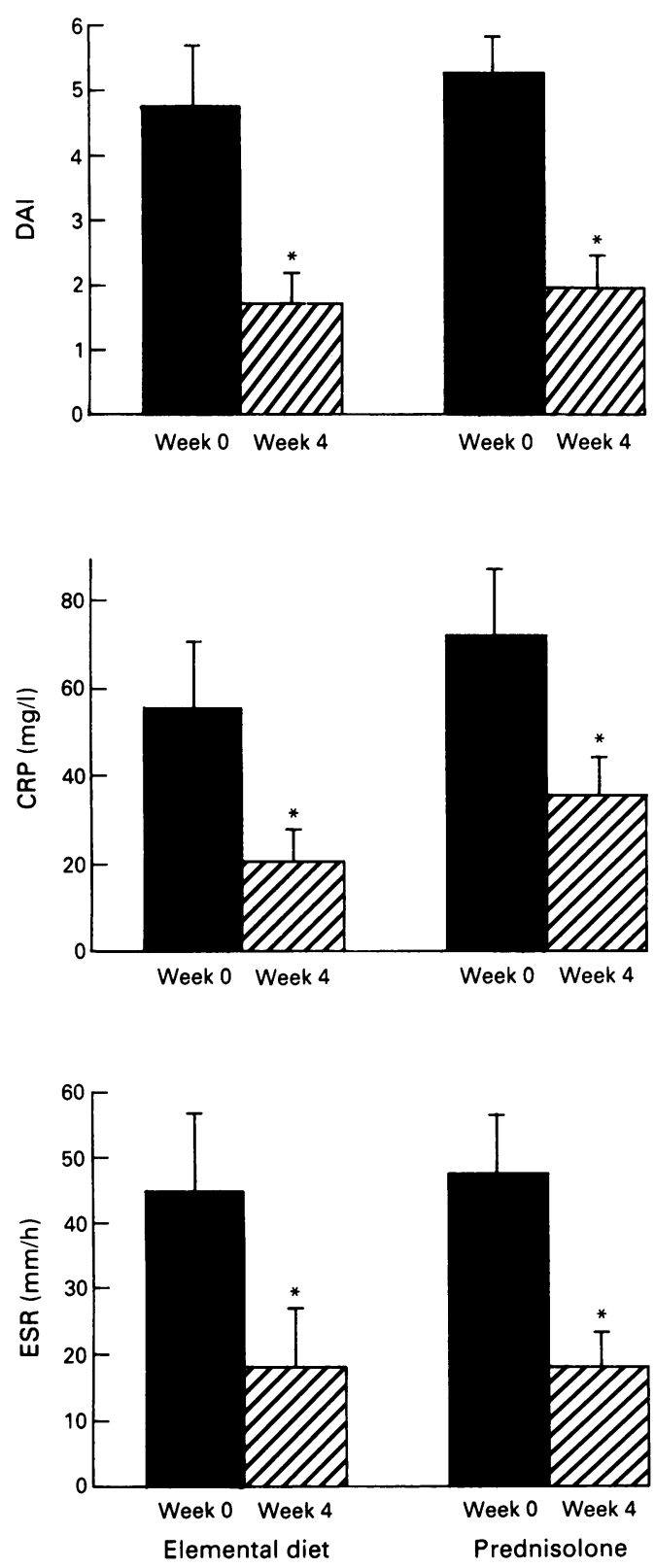

three of $20(15 \%)$ prednisolone treated patients and three of $13(23 \%)$ patients tolerating elemental diet.

Patients within each treatment arm who were considered malnourished at randomisation responded as well as nourished patients. In the group completing four weeks of elemental diet, there were similar significant $(\mathrm{p}<0.05)$ reductions in DAI from $4.6(0.9)$ to $2.2(1.0)$ in malnourished patients, and from $5 \cdot 0(1 \cdot 6)$ to $1 \cdot 3$ $(0.6)$ in nourished patients. In those receiving prednisolone, improvements $(\mathrm{p}<0.05)$ in DAI, from $4.4(0.7)$ to $1.9(0.6)$ in malnourished patients, and from $5.8(0.9)$ to $1.9(0.9)$ in nourished patients, were similar. Patients with a long duration of Crohn's disease and who had received specific treatment (steroids or surgery) in the past, showed a similar significant $(p<0.05)$ response to elemental diet, DAI decreasing from $6.3(1.4)$ to $2.2(0.8)$, as newly diagnosed patients, $3 \cdot 0(0 \cdot 6)$ to $1 \cdot 2(0 \cdot 7)$. On prednisolone, the DAI improvements $(\mathrm{p}<0.05)$ from $5 \cdot 1(0.9)$ to $1.7(0.6)$ in previously treated patients, and
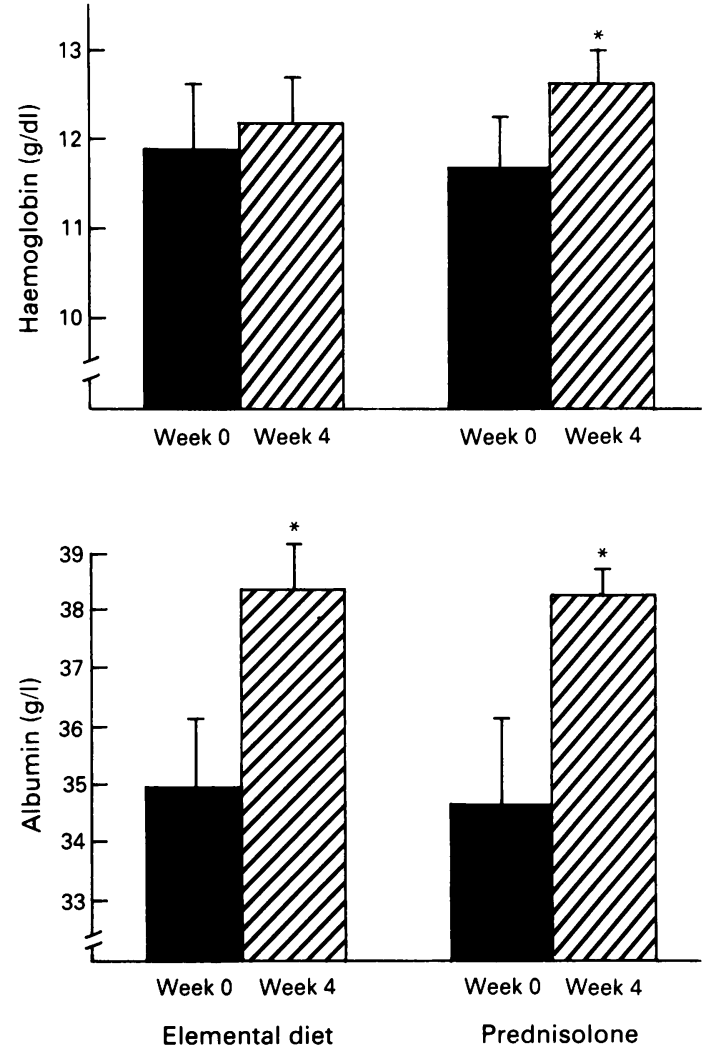

from $5 \cdot 6(0 \cdot 6)$ to $2 \cdot 1(1 \cdot 1)$ in newly diagnosed patients, were also similar.

Serial anthropometric measurements did not improve in those completing four weeks treatment with elemental diet. Within the prednisolone treated group, there was a significant increase in \%IBW and percentage standard MAC at four weeks (Table II).

\section{FOLLOW UP OF REMISSION}

During the 12 months prospective follow up of the 30 patients completing four weeks treatment, one patient (prednisolone treated) was lost to follow up at week 16. After the initial four weeks, patients treated with prednisolone were withdrawn from this drug over a further period of 6.5 $(2 \cdot 4)$ weeks. During this period, the average daily dosage of prednisolone was 12 (3) $\mathrm{mg}$.

Patients who had relapsed all had a DAI of at least four at the time of relapse. Those patients who had achieved remission on elemental diet relapsed earlier than those who had attained remission on prednisolone (Fig 2). The cumulative probability of maintaining remission at six months was 0.67 after treatment with prednisolone compared with 0.28 after treatment with eiemental diet, and at one year the probability of maintaining remission was 0.35 in the prednisolone group and 0.09 in the elemental diet treated group ( $p<0.05 ; \log$ rank test). At one year, remission was maintained in only one of the 11 elemental diet treated patients compared with six of the 19 prednisolone treated patients.

Within the elemental diet treated group, five patients with only small intestinal Crohn's disease tended to relapse later (mean remission period 29 weeks) than six patients who had colonic involvement (mean remission time 13 
TABLE II Anthropometric assessments before and after four weeks treatment with elemental diet or prednisolone

\begin{tabular}{|c|c|c|c|c|c|c|}
\hline & & $\begin{array}{l}\text { Weight } \\
(\mathrm{kg})\end{array}$ & $\% I B W$ & $\begin{array}{l}\% \text { Standard } \\
T S F\end{array}$ & $\begin{array}{l}\% \text { Standard } \\
\text { MAC }\end{array}$ & $\begin{array}{l}\% \text { Standard } \\
M A M C\end{array}$ \\
\hline Elemental diet & wk 0 & $60 \cdot 3(5 \cdot 6)$ & $91 \cdot 2(5 \cdot 4)$ & $72 \cdot 3(6 \cdot 8)$ & $83 \cdot 2(3 \cdot 2)$ & $86 \cdot 1(3 \cdot 3)$ \\
\hline & wk 4 & $59 \cdot 7(4.9)$ & $90 \cdot 6(4 \cdot 1)$ & $76 \cdot 0(5 \cdot 7)$ & $82 \cdot 7(2 \cdot 5)$ & $84 \cdot 3(2 \cdot 8)$ \\
\hline Prednisolone & wk 0 & $55 \cdot 6(3.5)$ & $90 \cdot 2(4 \cdot 0)$ & $74.9(7 \cdot 8)$ & $86 \cdot 5(3 \cdot 2)$ & $91 \cdot 2(3 \cdot 5)$ \\
\hline & wk 4 & $57 \cdot 1(3 \cdot 0)$ & $93.1(3.6)^{\star}$ & $80 \cdot 4(8 \cdot 5)$ & $90 \cdot 4(2 \cdot 6)^{\star}$ & $91 \cdot 9(3 \cdot 1)$ \\
\hline
\end{tabular}

*Week 4 result compared with week 0 result $\mathrm{p}<0.05$; abbreviations as in Table I; values expressed as mean (SEM). weeks), but this difference did not reach statistical significance.

\section{Discussion}

This trial has shown that elemental diet, when tolerated, is as effective as prednisolone in treating acute Crohn's disease in the short term, and confirms the result from the original study of O'Morain et al. ${ }^{5}$ In addition, we have shown that elemental diet is as beneficial in patients with longstanding disease as it is in newly diagnosed patients. Unlike previous studies comparing elemental diet with corticosteroids, in this trial we have stratified patients according to nutritional state before randomisation. Our results show that relatively well nourished patients respond equally well to elemental diet as those with a poor nutritional state. A larger number of patients would be necessary, however, to ensure that a small difference in response to elemental diet between nourished and malnourished patients was not being overlooked. Despite the improvements in DAI and laboratory tests, there was no improvement in body weight and anthropometrics in the elemental diet treated patients, whereas the prednisolone treated patients showed increases in \%IBW and percentage standard MAC.

Although elemental diet is known to decrease gastrointestinal protein loss, ${ }^{1+}$ faecal leucocyte excretion, ${ }^{6}{ }^{15}$ and improve intestinal permeability $^{1516}$ in acute Crohn's disease, its underlying mode of action remains unclear. Elemental

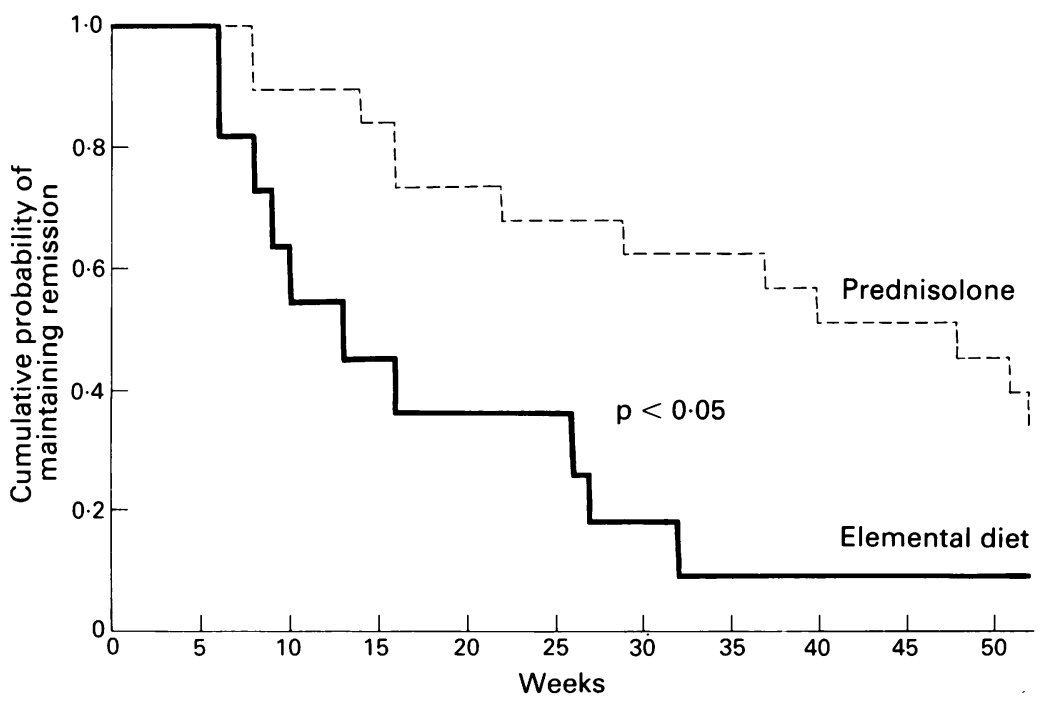

Figure 2: Cumulative probability of maintaining remission during one year follow up after treatment with prednisolone or elemental diet. diet does not exert its beneficial effect by improving nutrition alone,${ }^{17}$ and in this study remission with an elemental diet was achieved as readily in nourished as in malnourished patients.

Polymeric diets containing whole protein are as effective as elemental diets in improving nutrition $^{18}$ and are more palatable, but it is unclear whether isocaloric polymeric diets are as successful as elemental diets in inducing remission in acute Crohn's disease. ${ }^{19-22}$ Furthermore, nutritional treatment with enteral feeds in which nitrogen is provided as a hydrolysate of whole protein has been shown to be inferior to drug treatment in two large studies involving adults, ${ }^{23}{ }^{24}$ although a small study in children showed equal efficacy to corticosteroids. ${ }^{25}$ Preliminary results from the only trial directly comparing polymeric diet with corticosteroids do, however, suggest equal efficacy in inducing remission. ${ }^{26}$

It is widely believed that elemental diet is effective in Crohn's disease by achieving bowel rest. Its absorption is virtually complete in the proximal small intestine and there is minimal residue, so that the distal small intestine and colon are 'medically bypassed'. By virtue of its free amino acid content, however, elemental diet provides a powerful stimulus to pancreatobiliary secretions ${ }^{27}{ }^{28}$ to which inflamed ulcerated gut is then exposed. Moreover, following a study that failed to show superiority of intravenous nutrition over polymeric feeding or oral food with parenteral supplementation, it is now apparent that complete bowel rest is not essential for achieving remission in acute Crohn's disease with nutritional treatment. ${ }^{29}$

It has been suggested that in active Crohn's disease, dietary protein might gain access to the gut wall via ulcerated mucosa and cause secondary immune mediated tissue damage. ${ }^{5}$ A unique property of elemental diet, which might account for its effectiveness in acute Crohn's disease is its hypoallergenic nature. The absence of whole protein or peptides in elemental diet effectively removes dietary antigenic stimuli, which might otherwise provoke immune mediated damage on exposure to ulcerated gut mucosa. This may explain why two trials by the European Cooperative Crohn's Disease group, ${ }^{23}{ }^{24}$ both using a protein hydrolysate diet containing oligopeptides rather than solely free amino acids, have shown that enteral feeding is inferior to drug treatment with corticosteroids and sulphasalazine. Another difference in the enteral feeds used in these trials concerns the higher fat content of about $10 \%$ total energy, whereas the present and other trials, ${ }^{568}$ have used strictly elemental diets containing a very small amount $(2 \cdot 5 \%$ of energy $)$ of fat. ${ }^{2}$

Induction of remission using elemental diet avoids the side effects of repeated courses of steroids. ${ }^{30}$ In children with Crohn's disease, elemental diet also improves or reverses growth retardation. ${ }^{31}{ }^{32}$ Nevertheless, the unpalatability of orally given feed or the inconvenience of nasogastrically given feed, together with the total avoidance of other food requires considerable determination by the patient. Consequently $41 \%$ of our patients assigned to dietary treatment, despite hospitalisation, could not tolerate the 
elemental diet regimen and we could not reproduce the high compliance rates reported by others. ${ }^{33}$ If these non-compliant patients who failed to tolerate four weeks of elemental feeding are taken into account, then just $45 \%$ (10 of 22 ) patients originally randomised to receive four weeks of elemental diet achieved complete remission on diet alone. When compared with $85 \%$ (17 of 20 ) patients achieving remission with prednisolone, elemental diet is inferior $(p<0.05)$ on an intention to treat basis.

This trial is the first to prospectively follow elemental diet or prednisolone induced remission in adult patients over a period of a year. Some of the patients assigned to prednisolone did receive this drug for more than four weeks. The DAI and laboratory data, however, showed significant improvements at four weeks and continued prednisolone treatment does not protect patients in remission from further relapse. ${ }^{34}{ }^{35}$ The rate of relapse in elemental diet treated patients was higher than in those who had gained remission with prednisolone. Earlier relapse after elemental diet treatment has also been noted in paediatric patients. ${ }^{36} \mathrm{We}$ also found that patients with Crohn's disease affecting the colon were likely to relapse more rapidly, a finding that has been noted by others. ${ }^{33}{ }^{37}$

In conclusion, this study confirms that four weeks treatment with elemental diet, when tolerated, is as effective as prednisolone. The number of patients intolerant of the diet is disappointingly high and together with inability to sustain a prolonged remission, elemental diet treatment does have its disadvantages. Nevertheless it does have a primary role in managing acute Crohn's disease, and is an attractive alternative to corticosteroids when avoidance of the side effects of corticosteroids is essential

1 Harries AD, Heatley RV. Nutritional disturbances in Crohn's disease. Postgrad Med F 1983; 59: 690-7.

2 Seidman EG. Nutritional management of inflammatory bowe disease. Gastroenterol Clin North Am 1989; 18: 129-55.

3 Silk DBA, Payne-James J. Inflammatory bowel disease: nutritional implications and treatment. Proc Nutr Soc 1989; 48: $355-61$.

4 O'Morain CA. Does nutritional therapy in inflammatory bowel disease have a primary or an adjunctive role? Scand $\mathcal{F}$ Gastroenterol 1990; 25 (suppl 172): 29-34.

5 O'Morain C, Segal AW, Levi AJ. Elemental diet as primary treatment of acute Crohn's disease: a controlled trial. $B M \mathcal{F}$ 1984; 288: 1859-62.

6 Saverymuttu S, Hodgson HJF, Chadwick VS. Controlled trial comparing prednisolone with an elemental diet plus non26: 994-8.

7 Okada M, Yao T, Yamamoto T, Takenaka K, Imamura K, Maeda K, Fujita K. Controlled trial comparing elemental diet with prednisolone in the treatment of active Crohn's diet with prednisolone in the treatment of active
disease. Hepatogastroenterology 1990; 37: 72-80.

8 Seidman EG, Bouthillier L, Weber AM, Roy CC, Morin CL. Elemental diet versus prednisolone as primary treatment of Crohn's disease. Gastroenterology 1986; 90: 1625A

9 Frisancho AR. New norms of upper limb fat and muscle areas for assessment of nutritional state. Am $\mathcal{F}$ Clin Nutr 1981; 31 : $2450-5$

10 Rees RGP, Keohane PP, Grimble GK, Frost PG, Attrill H, Silk DBA. Tolerance of elemental diet administered withou starter regimen. BMF 1985; 290: 1869-70.

11 Harvey RF, Bradshaw JM. A simple index of Crohn's disease activity. Lancet 1980; i: 514

12 Statistical Bulletin Metropolitan Life Insurance Company. 1959: 40. Nov-Dec.
13 Peto R, Pike MC, Armitage P, Breslow NE, Cox DR, Howard $\mathrm{SV}$, et al. Design and analysis of randomised clinical trials requiring prolonged observation of each patient. $\mathrm{Br} \mathcal{F}$ Cancer requiring prolonge

14 Logan RFA, Gillon J, Ferrington C, Ferguson A. Reduction of gastrointestinal protein loss by elemental diet in Crohn' disease of the small bowel. Gut 1981; 22: 383-7.

15 Teahon K, Smethurst P, Pearson M, Levi AJ, Bjarnason I. The effect of elemental diet on intestinal permeability and inflammation in Crohn's disease. Gastroenterology 1991; 101 849.

16 Sanderson IR, Boulton P, Menzies I, Walker-Smith JA Improvement of abnormal lactulose/rhamnose permeability in active Crohn's disease of the small bowel by an elemental diet. Gut 1987; 28: 1073-6.

17 Teahon K, Pearson M, Levi AJ, Smith T, Bjarnason I. Improved nutrition is not an important mechanism by which elemental diets work in acute Crohn's disease. Gut 1990; 31: A624.

18 Jones BJM, Lees R, Andrews J, Frost P, Silk DBA. Comparison of an elemental and polymeric enteral diet in patien with normal gastrointestinal function. Gut $1983 ; 24: 78-84$

19 Giaffer MH, North G, Holdsworth CD. Controlled trial of polymeric versus elemental diet in treatment of active Crohn's disease. Lancet 1990; 335: 816-9.

20 Rigaud D, Cosnes J, Le Quintrec Y, Rene E, Gendre JP, Mignon M. Controlled trial comparing two types of entera nutrition in treatment of active Crohn's disease: elemental polymeric diet. Gut 1991; 32: 1492-7.

21 Raouf AH, Hildrey V, Daniel J, Walker RJ, Krasner N, Elias E, Rhodes JM. Enteral feeding as sole treatment for Crohn's disease: controlled trial of whole protein $v$ amino acid based feed and a case study of dietary challenge. Gut 1991; 32. $702-7$.

22 Park RHR, Galloway A, Danesh BJZ, Russell RI. Doubleblind controlled trial of elemental and polymeric diets as primary therapy in active Crohn's disease. Eur primary therapy in active Crohn's

23 Malchow H, Steinhardt HJ, Lorenz-Meyer H, Strohm WD, Rasmussen S, Sommer H, et al. Feasibility and effectiveness of a defined-formula diet regimen in treating active Crohn's disease: European Cooperative Crohn's Disease Study III. Scand F Gastroenterol 1990; 25: 235-44.

24 Lochs H, Steinhardt HJ, Klaus-Wentz B, Zeitz M, Vogelsang $\mathrm{H}$, Sommer $\mathrm{H}$, et al. Comparison of enteral nutrition and drug treatment in active Crohn's disease: results of the European Cooperative Crohn's Disease Study IV. Gastroenterology 1991; 101: 881-8.

25 Sanderson IR, Udeen S, Davies PSW, Savage MO, WalkerSmith JA. Remission induced by an elemental diet in small bowel Crohn's disease. Arch Dis Child 1987; 61: 123-7.

26 Gonzalez-Huix F, de Leon R, Acero D, Esteve $M$, Figa $M$ Abad A, et al. Total enteral nutrition with polymeric diets as primary treatment in Crohn's disease. Preliminary results of a controlled trial. Clin Nutr 1991; 10 (suppl 2): 47 .

27 Go VLW, Hofmann AF, Summerskill WHJ. Pancreozymin bioassay in man based on pancreatic enzyme secretion: potency of specific amino acids and other digestive products. f Clin Invest 1970; 49: 1558-64.

28 Hopman WPM, de Jong AJL, Rosenbusch G, Jansen JBMJ Lamers CBHW. Elemental diet stimulates gallbladder contraction and secretion of cholecystokinin and pancreatic polypeptide in man. Dig Dis Sci 1987; 32: 45-9.

29 Greenberg GR, Fleming CR, Jeejeebhoy KN, Rosenberg IH Sales D, Tremaine WJ. Controlled trial of bowel rest and nutritional support in the management of Crohn's disease. Gut 1988; 29: 1309-15.

30 Singleton JW, Law DH, Kelley ML Jr, Mekhiian HS, Sturdevant RAL. National Cooperative Crohn's disease study: adverse reactions to study drugs. Gastroenterology 1979; 77: 870-82.

31 Morin CL, Roulet M, Roy CC, Weber A. Continuous elemental enteral alimentation in children with Crohn's disease and growth failure. Gastroenterology 1980; 79: 1205-10.

32 Belli DC, Seidman E, Bouthillier L, Weber AM, Roy CC, Pletincx M, et al. Chronic intermittent elemental diet improves growth failure in children with Crohn's disease. Gastroenterology 1988; 94: 603-10.

33 Teahon K, Bjarnason I, Pearson M, Levi AJ. Ten years' experience with an elemental diet in the management of Crohn's disease. Gut 1990; 31: 1133-7.

34 Summers RW, Switz DM, Sessions JT, Becktel JM, Best WR, Kern F, et al. National cooperative Crohn's disease study: Kern F, et al. National cooperative Crohn's disease study:
results of drug treatment. Gastroenterology 1979; 77: 847-69.

35 Malchow H, Ewe K, Brandes JW, Goebell H, Ehms H, Sommer H, et al. European cooperative Crohn's disease study: results of drug treatment. Gastroenterology 1984; 86: 249-66.

36 Seidman EG, Lohoues MJ, Turgeon J, Bouthillier L, Morin $\mathrm{CL}$. Elemental diet versus prednisolone as initial therapy in Crohn's disease: early and long term results. Gastroenterology 1991; 100: A250.

37 Giaffer MH, Cann P, Holdsworth CD. Long-term effects of elemental and exclusion diets for Crohn's disease. Aliment Pharmacol Therap 1991; 5: 115-25. 